\title{
RICARDO AGUILAR MELANTZÓN: ESCRITOR Y ACTIVISTA CHICANO
}

Axel Ramírez*

\begin{abstract}
RESUMEN: Este artículo fue presentado como una semblanza del escritor y activista chicano Ricardo Aguilar Melantzón en una Mesa Redonda, que organizó el Centro Coordinador y Difusor de Estudios Latinoamericanos (CCYDEL) el 13 de octubre de 2004, en memoria de quien fuera uno de los principales investigadores del proyecto desarrollado en este Centro La piedra y la flama: Ios latinos en Estados Unidos. En dicho homenaje participaron también Juan Bruce-Novoa, de la Universidad de California-Irvine, Judith Hernández Mora de la Universidad Metropolitana de Caracas, Venezuela, así como dos distinguidas universitarias: Patricia Casasa García (ENEOUNAM) y Leticia Urbina (FES-Acatlán). Por razones tipográficas la semblanza tuvo que cambiar su sentido original.
\end{abstract}

PALABRAS ClAVE: Literatura chicana, Cultura chicana, Identidad, Frontera.

ABSTRACT:This article was read as a portrait of Chicano writer and activist Ricardo Aguilar Melantzón in a roundtable organized by the Centro Coordinador y Difusor de Estudios Latinoamericanos (CCyDEL), on October 13th 2004 , in memory one of the main researchers of this Center's project, La piedra y la flama: Ios latinos en Estados Unidos.

KEY WORDS: Chicano literature, Chicano culture, Identity, Border.

\section{INTRODUCCIÓN}

Ante la imperiosa necesidad de abordar académica y científicamente a la comunidad chicana en relación al presente y futuro de las relaciones bilaterales México-Estados Unidos, y frente a la urgencia geopolítica de definir la identidad nacional, la Universidad Nacional Autónoma de México decidió crear en 1988 el Área de Estudios Chicanos, como parte del Cen-

* Centro Coordinador y Difusor de Estudios Latinoamericanos, UNAM (axel@servidor. unam.mx). 
tro de Enseñanza para Extranjeros, para realizar, estudiar y desarrollar sistemas de información relativos a los aspectos políticos, económicos y socioculturales de los chicanos en Estados Unidos, que permitieran un mejor acercamiento a ese grupo. Los antecedentes inmediatos se remontan a la década de los años cuarenta cuando se inauguró un programa de difusión de la Cultura Mexicana en la Ciudad de San Antonio, Texas, dirigido primordialmente a la comunidad de origen mexicano.

Con el paso del tiempo, la Universidad Nacional Autónoma de México incrementó su interés por los mexicanos "del otro lado" y decidió organizar la Semana de la Sociedad Chicana en 1986, en la que se conjugaron los esfuerzos de la Coordinación de Difusión Cultural, la Dirección General de Difusión Académica, el Centro de Relaciones Internacionales de la Facultad de Ciencias Políticas y Sociales, la Escuela Permanente de Extensión de la UNAM en San Antonio (EPESA) y el propio Centro de Enseñanza para Extranjeros. ${ }^{1}$ Posteriormente, en 1987, se organizó conjuntamente con la Secretaría de Educación Pública (SEP), el denominado Segundo Encuentro Chicano, orientado a discutir y analizar los efectos mediatos e inmediatos de la promulgación de la Ley Simpson-Rodino (1986), así como sus efectos paralelos. El Encuentro fue inaugurado por el entonces presidente de la República, licenciado Miguel de la Madrid Hurtado, en presencia del señor rector de nuestra universidad en aquella época doctor Jorge Carpizo, contando con una variada gama de actividades como cine, teatro, muestra de pintura, cinematografía etc., al que acudió un público bastante numeroso.

Una vez consolidada el Área de Estudios Chicanos, se vislumbró la necesidad de otorgar continuidad a este tipo de eventos, por lo que se organizó el Encuentro Chicano 1998 inscrito en el tema específico de "Los chicanos en el futuro de las relaciones bilaterales México-Estados Unidos", añadiéndose una nueva modalidad: dedicar el Encuentro a un personaje relevante de la comunidad chicana. Se seleccionó a Willie Ve-

1 Axel Ramírez, "Introducción” a Axel Ramírez [comp.], Encuentro Chicano México 1998, México, CEPE-UNAM, 1992, pp. 7-10. 
lásquez, militante decidido que logró muchas cosas positivas para la comunidad tejana-mexicana. Willie fue un hombre que nos heredó la marca indeleble de su contribución básica para propiciar un cambio dentro del sistema político anglosajón a favor de los chicanos. ${ }^{2}$ Su eterno mensaje señala que debemos sentirnos orgullosos por la enorme contribución de los mexicanos y chicanos al desarrollo y consolidación de Estados Unidos como nación, así como su postulado que remarca el influjo de las fuerzas multiculturales que dieron origen a Texas demuestra la grandeza de su espíritu, la claridad de su entendimiento, su sed de justicia, su responsabilidad política y su determinación. ${ }^{3}$

\section{El MOVIMIENTO CHICANO}

Muy frecuentemente suele pensarse que el Movimiento Chicano se originó por primera vez en la década de los años sesenta, aunque en realidad de lo que debe hablarse es de un "resurgimiento" o renacimiento del mismo, manifestado por toda una serie de protestas sociales que tuvieron su auge en el suroeste de Estados Unidos. Esta etapa histórica fue clave para gestar una verdadera revolución cultural que tuvo como característica fundamental el choque generacional, lo que propició el despertar de la conciencia en algunos militantes.

La juventud estadounidense se manifestó de diversas formas intentando llegar a ocupar un lugar en la sociedad. La represión de estudiantes y obreros así como el encarcelamiento de algunos portavoces radicales, como fue el caso del pacifista David Harris; la marcha hacia Washington en 1965, los disturbios ocurridos durante la Convención del Partido Demócrata de 1968, la huelga en la Universidad de Indiana durante un periodo de intranquilidad en 1969, la irrupción del ejército en la Universidad de Kent, donde hubo heridos y varios estudiantes encarcelados, eran sólo una muestra del enfrentamiento generacional.

2 Ibid., p. 9.

3 Loc. cit. 
Esta turbulenta época de los años sesenta dejó su marca indeleble en varias partes del mundo. En Estados Unidos representó una etapa de profundas convulsiones sociales en las que destacó el embate de una nueva generación que propugnaba por un cambio radical en las estructuras profundas de su país. La Baby Boom Generation encarnó la instancia prioritaria para la demanda en busca de una sociedad más justa e igualitaria.

El Movimiento de Libre Expresión de Berkeley puso de manifiesto la emergencia de una contracultura, la que desató una violenta controversia a partir de Hair (1968) la valiente comedia rock-musical que montó en el escenario la cultura de los hippies y de Woodstock (1969), el festival de rock al aire libre en Nueva Cork. ${ }^{4}$

Este periodo de free-speech les permitió a los jóvenes por primera vez en muchos años hacerse escuchar en el seno de una sociedad conservadora y puritana, que se oponía a un cambio tan radical. La comunidad afro-americana se manifestó por medio del Poder Negro (Black Power); surgió el Movimiento por los Derechos Civiles, así como el rechazo abierto a la guerra de Vietnam.

La carrera armamentista y la industria nuclear no tuvieron mucha aceptación en el grueso de la población estadounidense que ya vislumbraba las consecuencias de la misma. Las mujeres, por medio del Movimiento de Liberación Femenina, exigían la supresión inmediata de su opresión. De esta manera, los denominados grupos "minoritarios" iniciaron su largo camino de protesta contra la discriminación racial de que eran objeto, oponiéndose a la marginación social que experimentaban diariamente.

En este binomio de "radicalismo" y "liberalismo" comenzaron a emerger grupos organizados de lucha como respuesta al malestar social que se dejaba sentir en el ambiente, y uno de esos grupos fue precisa-

4 Richard Dorson, Historia legendaria de los Estados Unidos: el folklore americano desde el periodo colonial hasta el momento presente, Barcelona, Aura, 1978, p. 311.

5 Hisauro Alvarado Garza, Nationalism, Consciousness and Social Change; Chicano Intellectuals in the U.S., Berkeley, University of California, Ph.D. Dissertation, 1984 (mecanografiada). 
mente El Movimiento Chicano, cuyos antecedentes pueden remontarse hacia varias décadas atrás e inclusive al siglo pasado.

Las protestas encabezadas por César Chávez (1962, 1964 y 1965), Reies López Tijerina (1963, 1966 y 1967), Rodolfo “Corky” González (1969 y 1970) y José Ángel Gutiérrez (1967 y 1970), conjuntamente con los sucesos acaecidos en Parlier, California, donde no se permitió a unos niños afro-americanos abordar el autobús escolar; la obtención de dos alcaldías por mexicano-americanos, la mayoría de éstos en dos Juntas de Educación, así como la obtención de dos ayuntamientos en Cristal City, Tejas, demostraron que el nacionalismo cultural, al igual que la identificación de un enemigo común, unificaba a la población descendiente de mexicanos.

En el ámbito estudiantil también emergieron varios grupos. La United Mexican American Students (UMAS), Mexican American Students Confederation (MASC), Movimiento Estudiantil Chicano de Aztlán (MECHA), y más recientemente la Mexican American Youth Organization (MAYO).

Quizá el extremo de la lucha chicana lo representaron los Brown Beretts o Boinas Café que surgieron en 1967 en el oriente de la ciudad de Los Ángeles, con la idea de un grupo de corte paramilitar que polarizó la atención de la juventud chicana y causó un fuerte impacto entre los estudiantes, quienes veían en la acción frontal el método más adecuado de enfrentamiento.

\section{UN ESCRITOR CHICANO}

De acuerdo con Juan Bruce-Novoa para el estudioso de la literatura chicana su novedad es una bendición a medias. La mayoría de las obras son recientes y aún hay pocos textos. Uno se encuentra con la envidiable posición de poder leer con relativa facilidad todas las principales obras chicanas, y en algunos géneros, por ejemplo la novela, se vuelve más complicado cada año que pasa. ${ }^{6}$ Ricardo Aguilar Melantzón fue un

6 Juan Bruce-Novoa, La literatura chicana a través de sus autores, México, Siglo XXI, 1983, 293 pp. 
escritor que se preocupaba mucho por hacer llegar sus obras al público fronterizo, chicano y mexicano.

Narrador, poeta, crítico literario, investigador, traductor, Ricardo Aguilar es parte intrínseca de esos vientos con olor a frontera, tema que constituía su verdadera pasión ya que se consideraba y asumía como un ente fronterizo aunque también era chicano y orgullosamente mexicano. De hecho participó activamente en el Movimiento y en él Ricardo Aguilar Melantzón fincó su ideología, en ese contexto del binomio nacionalismo-radicalismo que ya se ha explicado.

Nacido en El Paso, Tejas, vivió en Ciudad Juárez durante 39 años; así, entre esas dos ciudades gemelas se fue desarrollando la vida de quien llegaría a ser ese gran escritor por desgracia ya desaparecido. Comenzó a escribir desde muy joven, a los 12 años de edad, cuando le enviaba cartas a un amigo que se encontraba estudiando en la Universidad Nacional Autónoma de México y quien después llegaría a ser un famoso abogado internacionalista. Ese amigo fue precisamente quien descubrió el talento literario de Ricardo Aguilar al señalarle que su correspondencia la leía como si fuera un buen ensayo. A partir de este hecho, se convirtió en un lector obsesivo y compulsivo, a pesar de que solamente cursaba sus estudios en la Escuela Primaria María Martínez ubicada en el Primer Distrito, en distrito bravo de Ciudad Juárez, en donde aprendió el sentido mágico de las palabras así como el estilo literario bajo la influencia del profesor Valdíviez, un maestro autodidacta.

Por medio de su padre aprendió el gusto por la poesía, lo que lo convirtió en poeta. Se adentró en Gabriela Mistral, Pablo Neruda, Rosario Castellanos, etc., paralelamente leyó a Charles Dickens, Isaac Asimov, Bradbury, Lawrence y Hemingway llevándolo a realizar una comparación entre ambas literaturas; por supuesto, también se compenetró con todas las figuras del boom literario latinoamericano. Fue precisamente en este medio donde se forjó el Ricardo Aguilar escritor.

Su prolífica pluma nos ha brindado los ensayos: Efraín Huerta, La frontera: Letra y Risa; las antologías: Palabra nueva; Cuentos chicanos, Palabra nueva: poesía, Traven para jóvenes, Cuento chicano del siglo $X X$. Los libros de poesía: Caravana enlutada y En son de la lluvia. La 
novela Madreselvas en flor. La serie de cuentos intitulados Aurelia. Las traducciones La vida loca/siempre corriendo de Luís J. Rodríguez y Camino a Tamanzuchale de Ron Arias, traducción que llevó a cabo con Beth Pollock, y Por el amor a Pedro Infante de Denise Chávez. Elaboró el diccionario Glosario del caló de Ciudad Juárez y escribió otras obras como: A Barlovento y Lo que el viento a Juárez, entre otras muchas.

Con Madreselvas en flor Ricardo obtuvo el Premio José Fuentes Mares en Letras Chicanas en 1988, galardón que otorgaba la Universidad Autónoma de Ciudad Juárez por desgracia ya desaparecido. Espacio que compartieron con Ricardo los autores chicanos Miguel Méndez, Fausto Avendaño, Juan Bruce-Novoa, Juan Esteban Arellano, etcétera.

Don José Fuentes Mares (1919-1986), historiador, narrador, dramaturgo, profesor chihuahuense, había soñado con la idea de ofrecer un premio nacional. Varios años antes de su sentida desaparición mantuvo conversaciones con maestros y funcionarios de la Universidad Autónoma de Ciudad Juárez con el objeto de impulsar un proyecto concreto. En 1986, la universidad institucionalizó el premio anual de literatura mexicana con el nombre del distinguido pensador chihuahuense, don José Fuentes Mares. Dos años más tarde, en virtud de nuestra situación geográfica fronteriza, dicho reconocimiento incluyó la modalidad en letras chicanas. ${ }^{7}$

En el verano de 2003, Ediciones y Gráficos EÓN, la Universidad de Tijuana y la Universidad Veracruzana editaron la obra de Ricardo intitulada Que es un soplo la vida. Trilogía de la frontera con bastante éxito. Madreselvas en flor (1987), Aurelia (1990) y A Barlovento (1999) son las obras que integran este volumen y que constituyen la obra narrativa quizá más sobresaliente y notoria de Ricardo Aguilar aunque a fin de cuentas toda su obra lo es. Estos tres ensayos que pueden leerse como un solo libro o como varios libros son una intención consciente en este autor, aprendida del Movimiento Negro de los años sesenta que le mos-

7 Ysla Campbell [coord.], Iba a decir que oscurece. Diez años del Premio José Fuentes Mares, Ciudad Juárez, Universidad Autónoma de Ciudad Juárez, 1997, p. 7. 
trara que debe de existir una imperiosa necesidad de escribir todas estas cosas para no perder la cultura y la memoria histórica.

Lo primero que se desprende de esta obra es que para nuestro autor las ciudades de El Paso, Las Cruces y Ciudad Juárez no son ciudades, sino que más bien constituyen una región que sin lugar a dudas impregnó la atmósfera de Ricardo Aguilar, por medio de la cual el autor buscaba definir su identidad de fronterizo. En cierta ocasión señaló que se ha escrito bastante acerca de la experiencia de chicanos y mexicano-americanos, pero muy poco acerca del otro lado. De hecho, esta trilogía se enfoca en la experiencia mexicana desde el punto de vista de alguien que realmente la conoce y la entiende perfectamente bien.

\section{MADRESELVAS EN FLOR}

A un compás de tango, pero de un tango paseño-juarense, esta parte o este libro nos describe claramente la experiencia de los chicanos de esa región que es totalmente diferente de la de los chicanos de tierra adentro, los del suroeste y muy lejos de la de los chicanos del noroeste, que constituyen otra variante cultural. Lo hace a través de un lenguaje muy particular orientándose hacia la discriminación de los chicanos al interior de las fuerzas armadas estadounidenses, que se convirtieron en la minoría más condecorada de la Segunda Guerra Mundial y de Corea; chicanos que fueron a combatir engañados por el falso concepto de la democracia estadounidense, demostrando su patriotismo a un precio muy alto.

También podemos encontrar la imagen del "barrio" como reflejo de la historia de la población mexicana en Estados Unidos que actualmente suma 20640 711, significando el 58.50\% de los "latinos" en aquel país y que arribaron de manera individual, grupal o por medio de programas oficiales como el Primer Programa Bracero (1917-1918) o el Segundo Programa Bracero (1942-1964), que llevó a muchos de nuestros conna-

8 US Census Bureau, Census 2000, Summary File 1. 
cionales para esas tierras como parte del binomio oferta-demanda, de manera documentada o indocumentada.

El autor nos hace notar la tendencia de los inmigrantes a aglutinarse territorialmente de acuerdo a su lugar de procedencia; estos enclaves no sólo proporcionan albergue y protección sino que generan, al mismo tiempo, un fuerte sentido de pertenencia.

Raúl Morín autor de la obra Among the Valiant señala en sus páginas que durante el reclutamiento los chicanos se enlistaban por barrios, como una clara muestra de identidad territorial. El Paso, o "El Chuco" como se le designa en spanglish, no fue la excepción.

El problema del choque cultural educativo también sale a flote en Madreselvas en flor, enfrentamiento con una educación ajena a la cultura y al medio, el problema de la discriminación racial en donde un alumno bilingüe es considerado en desventaja por el sistema educativo estadounidense.

Asimismo, Ricardo Aguilar nos lleva de la mano al fascinante mundo de los Low riders, su comportamiento, sus códigos, sus simbolismos para terminar subiendo al lector en una motocicleta y recorrer el amplio escenario de las variadas tierras de Nuevo México, trama que recuerda mucho a Julio Cortázar en su cuento La noche boca arriba, donde precisamente una motocicleta desempeña un papel muy importante. A Ricardo Aguilar le entusiasmaba transitar en su Susuki por la Santa Fe Street, por Sunset Heights o por algún Freeway, mientras que el personaje de Cortázar mas bien lo lleva hasta los aztecas. Madreselvas en flor es una expresión lírica del tango Madreselva de Luís César Amadoni con música de Francisco Canaro que para Aguilar Melantzón significaba: su madre, su padre, sus hermanos, el jardín, el abuelito, la localidad y todos los recuerdos en torno a ello. Esta obra tuvo un tiraje inicial de 1500 ejemplares, mismos que se agotaron de inmediato.

De hecho, esta parte o este libro examina, con una minuciosidad etnográfica, la vida de residentes mexicanos ficticios en el área de Ciudad Juárez-El Paso, cómo crecen y viven en esa tercera cultura fronteriza. 
La Aurelia de Ricardo Aguilar Melantzón nos conduce irremediablemente a la idea de la Aurelia de Gerard de Nérval (1855) en donde, en la primera parte, comienza señalando que "la revelación es una segunda vida", obra en la que se habla también de un mundo invisible, de la muerte como un determinante del "yo", que es otra forma de continuar la existencia: un sótano oscuro y vago que se aclara poco a poco desembarazándose de las tinieblas de las sombras de la noche y de las pálidas figuras inmóviles del Limbo, lo que el autor Swedenborg llamaba Memorabilia.

Sin embargo la Aurelia de Ricardo Aguilar es la imagen de la abuela materna del mismo nombre, una mujer de carácter increíblemente fuerte pero solitaria; mujer autoritaria procedente de Batopilas, en el Cañón del Cobre, Chihuahua. Esa Aurelia, alta y robusta, con una visión quijotesca de las cosas, llegó de la sierra de Ciudad Juárez llevando con ella todo un bagaje cultural. O tal vez, debido a la afición del autor por la historia romana, la Vía Aurelia —una ruta muy importante para llegar a Roma- echó a volar su imaginación, o fue una conjunción de ambas. Le puso por título Aurelia porque constituye un raconte en la colección, una narrativa, una suerte de ensayo pero con un nombre.

Lo que Aguilar Melantzón pensó hacer con su libro Aurelia, como una vez comentó, fue unir los ríos: ríos de su familia porque Aurelia era una clase de río, fuerte y poderoso; era vida y muerte al mismo tiempo, un huracán vital fluyendo por medio de las voces de su familia. Para el propio autor, los ríos eran en gran parte un elemento femenino porque el agua otorga vida a la agricultura, produce alimentos y todas esas cosas eran bellas para Ricardo Aguilar.

Los recuerdos de South El Paso también afloran de manera natural, ubicándolo en el trolebús que bajaba por El Paso Street hasta llegar a Stanton y experimentar la sensación de estar frente al Puente Negro, lugar de cruce de indocumentados y en donde muchos de ellos han perdido la vida. El viaje de Ciudad Juárez a El Paso constituye una experiencia 
normal para la gente porque para ellos no existen dos ciudades, es una sola. Aurelia analiza la experiencia de varios individuos o familias que se habían quedado guardados en la mente del autor y que a través de su pluma ágil los compartió con nosotros.

\section{A BARLOVENTO}

Este también puede ser un libro y muchos libros a la vez; aunque el escenario es mucho más fronterizo que chicano en la condición del protagonista: un padre de familia. Es un magnífico ensayo manejado con excelentes marcos de referencia líricos y narrativos. En esta obra el autor se muestra nuevamente como un antropoliterato que nos advierte sobre los problemas de la modernidad y de la identidad de Ciudad Juárez.

Si la antropoliteratura o la antropología literaria puede ser definida como: "el estudio de la asimilación de símbolos, cargas sentimentales, rituales, semántica, planes tiempo y espacio, que permite a su vez la descripción de los personajes y su ambientación en un texto literario", entonces Ricardo Aguilar era eso: un antropólogo de campo que dominaba a la perfección los métodos y técnicas de la investigación que Malinowski denominó observación participante, ya que Aguilar Melantzón no sólo observaba y analizaba, participa activamente con su entorno cultural.

En A Barlovento igualmente nos conduce al intrincado problema del exilio, con todos sus dilemas existenciales y, por supuesto, a los exiliados, a los que José Gaos prefería llamar transterrados. Igualmente constituye una reflexión sobre la vida y la muerte; el amor, la vida rutinaria y cotidiana de Ciudad Juárez. Una obra escrita sin lugar a dudas para encontrar respuesta a la escurridiza condición humana. Iniciada en

9 Axel Ramírez, "La filosofía del pensamiento chicano. Only the Good Times, de Juan Bruce-Novoa", en Axel Ramírez y Patricia Casasa [eds.], Actas del Séptimo Congreso Internacional de Culturas Latinas en Estados Unidos, México, UNAM/Secretaría General, 1997, pp. 223-230. 
1985, es un ensayo de introspectiva sobre un viaje a través de nuestra frontera norte.

En la obra de Ricardo Aguilar se nota un "yo" crítico, autocrítico y autobiográfico; no podía ser de otra manera. Dicha obra tiene un principio y un fin, a través de los cuales nos muestra que la vida es verdadera, a veces alegre, otras triste y en muchas ocasiones trágica; sin embargo, lo supo conjugar de una manera tan lúcida que lo pone al alcance de cualquier lector.

Después de leer a Ricardo Aguilar ya no somos habitualmente nosotros mismos, sino unos entes capturados por el embrujo de una pluma sumamente hábil que nos conduce, irremediablemente, a sentirnos también fronterizos, una zona poblada de gente de carne y hueso. En eso consiste la magia de Ricardo Aguilar Melantzón.

Lamentablemente falleció el mes de septiembre de 2004 en E1 Paso, Tejas. Aunque no esperaba tan pronto la muerte ya la presentía.

Mientras me marcaban la ceniza en la frente me pregunté si sería verano o invierno, día o noche, que estaría acostado en mi propia caja gris. Aún no me ha golpeado totalmente la vejez pero me canso por la tarde y en la noche. Entre más imagino, advierto que las cosas más diferentes se parecen a las más iguales. Ya casi nada me sorprende. Será que cada año reconozco las mismas cosas, un poco cambiadas pero no mucho. Tal vez por eso sea hermosa la ignorancia pues permite aprender algo verdaderamente nuevo. Como todas las tardes, como todos los años hoy visité a mi padre. Me fijé en las canas y en la sonrisa. No me cabe en la cabeza que algún día no esté pues siempre ha estado. Me da terror pensarlo, pues él siempre ha derrochado la fuerza, la constancia, la serenidad que todos conocemos, que nunca cuestionamos, algo que tiene que estar como los cerros y la arena. ${ }^{10}$

${ }^{10}$ Ricardo Aguilar Melantzón, "Última espera", en Campbell, op. cit., p. 109. 


\section{CONCLUSIONES}

Con muy contadas excepciones en México, sólo algunos académicos que se encuentran ligeramente involucrados en el tema están interesados en lo que escriben los chicanos, y desde luego, la interpretación que hacen de este corpus literario se ve seriamente afectado por la mentalidad mexicana que abierta o solapadamente continúa rechazando lo chicano. Se pueden presentar casos de efectos momentáneos en este público cautivo, pero impresiones profundas, duraderas... definitivamente no, como lo acotara muy acertadamente Ron Arias. Las grandes obras de la literatura chicana, cuentos, novelas, poemas, etc., no son más que una suerte de "curiosidad" para muchos lectores en México, quienes siempre han pensado que los chicanos "no saben escribir" y lo que es peor, ubican la literatura chicana como un apéndice de la literatura estadounidense o de la mexicana, negándole el derecho que por propios méritos se ha ganado la escritura de los chicanos, tan apreciada en Europa y tan desdeñada en nuestro país.

Como una gran ironía, el maestro José Fuentes Mares declaró en una conferencia de prensa que "todos los mexicanos llevan un chicano en potencia", lo que molestó de manera notoria. ¿Será que a los mexicanos les da temor verse reflejados en el espejo de lo chicano?, como se cuestiona Tino Villanueva. Este mismo autor resume de manera crítica el pensamiento mexicano frente a lo chicano

el chicano[...] le ha sido repugnante tanto a una clase mexicana como a otra. Por eso, si tuviera que formular algún agravio al mexicano, sería el de su fastidiosa incomprensión: el de ignorar hechos históricos y políticos que modificaron bruscamente el curso de la civilización indo-hispana de lo que serían los Estados Unidos. ${ }^{11}$

${ }^{11}$ Tino Villanueva [comp.], Chicanos. Antología histórica y literaria, México, FCE, 1980, pp. 44-45. 
Juan Bruce-Novoa resulta muy ilustrativo

[...]no somos mexicanos, no queremos ser mexicanos. Gran parte de la literatura está de acuerdo: somos otra cosa[...] Hasta ahora hemos llegado aquí, siempre, como mexicanos menos, mexicanos más, pero mexicanos en algo inauténtico, porque ustedes son el punto cero de la autenticidad[...] Tienen que aceptar que somos otra cosa: relacionados, pero otra cosa[...] Pero no somos México. No y no, y no. ${ }^{12}$

Por otro lado, Ricardo Aguilar nos dejó como legado la idea de que el pensamiento mexicano ha tenido una gran influencia sobre todo en la expresión literaria chicana, que se inspiraba, en una primera etapa, en las novelas de la Revolución mexicana, que el arte y la literatura nos permiten también conocer mejor al chicano, ya que muchas imágenes que carecen de amplitud de visión, permiten ser aclaradas.

Por medio de su obra literaria, Aguilar Melantzón nos deja ver que es muy complicado para la población mexicana entender cómo los chicanos pueden haber perdido la cultura y resucitar como "pochos" a los que José Vasconcelos criticó rudamente, o como "cholos" y renegados que le han volteado la espalda a la herencia mexicana y que no saben hablar o fingen no hablar castellano, mucho menos escribirlo.

El filólogo mexicano Ilan Stavans está a punto de terminar su traducción de Don Quijote al spanglish o inglañol. Esto será, sin lugar a dudas, un gran reconocimiento para la comunidad chicana, quizá con ello se apuntale el señalamiento del insigne maestro José Fuentes Mares y tal vez hasta pudiera ampliarse.

12 Juan Bruce-Novoa, Encuentro Chicano México 1987, México, CEPE-UNAM, 1987, p. XXXIII. 


\section{BIBLIOGRAFÍA}

Aguilar Melantzón, Ricardo, "Madreselvas en flor" en Puerto del Sol, vol. 29, núm. 1, Las Cruces, New Mexico State University, Spring, 1994, pp. 101-162.

, A Barlovento, Torreón, Editorial del Norte Mexicano, 1999, $251 \mathrm{pp}$.

Cuento chicano del siglo XX. Breve antología, México, Ediciones Coyoacán, 1993, 293 pp.

y Cecilia Pino, Antología del cuento chicano, Toluca, Universidad Autónoma del Estado de México, 1992, 162 pp.

y Ana Brewington [traductores], La vida loca; el testimonio de un pandillero en Los Ángeles, USA, Simon and Schuster, 1993, 284 pp.

y Socorro Tabuenca, Lo que el viento a Juárez, Torreón, Editorial del Norte Mexicano, 2000, 165 pp.

GaOna, María Eugenia, Antología de la literatura chicana, México, CEPE-UNAM, 1986, 284 pp.

LOMELÍ, FRANCISCO A. y KARIN IKAS [eds.], U.S. Latino Literaturas and Cultures; Transnacional Perspectivas, Heidelberg, Universitätsverlag, 2000, $330 \mathrm{pp}$.

RAMíREZ, AXEL [coord.], Encuentro Chicano México 1987. Memorias, México, CEPE-UNAM, 1987, 341 pp.

[comp.], Encuentro Chicano México 1988, México, CEPE-UNAM, 1992, $241 \mathrm{pp}$.

[comp.], Chicanos el orgullo de ser. Memoria del Encuentro Chicano México 1990, México, CEPE-UNAM, 1992, 195 pp.

La comunidad chicana en Estados Unidos: retrospectiva histórica, México, Ediciones La Viga, 1992, 81 pp. (Biblioteca Preparatoria 7 , núm. 4).

y María E. GaOna, Manifiestos Chicanos, México, Coordinación Redifusión Cultural-UNAM, 1988, 22 pp. (Serie Los Nuestros). 
y Patricia Casasa [eds.], Actas del Séptimo Congreso Internacional de Culturas Latinas en Estados Unidos, México, UNAM/Secretaría General/CEPE, 1997, 300 pp.

y C.B. TORRES, "Introducción" a La Herencia/The Heritage. I Encuentro de Escritoras Chicanas, México, UNAM/SRE, 2003, $132 \mathrm{pp}$.

RENDÓn, ARMANDO B., Chicano manifesto; The History and aspirations of the second largest minority in America, Nueva York, Macmillan Company, 1971, 337 pp.

SALDÍVAR, RAMÓn, Chicano narrative; The Dialectics of Difference, Madison, The University of Wisconsin Press, 1990, 250 pp.

TATUM, Charles, La literatura chicana, México, SEP, 1986, 261 pp. [ed.], New Chicana/Chicano Writing, Tucson, The University of Arizona Press, 1992, 185 pp. 